\title{
The effects of aerobic exercise in water on perceived pain and heart rate variability in women with fibromyalgia
}

\author{
Matías M. Riquelme1', Claudia A. Melipillán ${ }^{1,2}$, Alexis A. Bacon'1, Oscar A. Niño-Méndez³, Cristian A. Núñez-Espinosa' \\ 'Escuela de Medicina. Universidad de Magallanes. Punta Arenas. Chile. ${ }^{2}$ Corporación de Rehabilitación Club de Leones Cruz del Sur. Punta Arenas. Chile. ${ }^{3}$ Facultad de Ciencias del \\ Deportey Educación Física. Universidad de Cundinamarca. Colombia.
}

doi: 10.18176 /archmeddeporte.00020

Received: 12/06/2020 Accepted: 01/12/2020

Key words: Fibromyalgia. Pain. Autonomous Nervous System. Exercise.

\section{Summary}

Fibromyalgia is a disease characterized by conical pain associated with autonomic dysregulation of the sufferer, without many treatment alternatives. The objective of this study was to find out the relationship between physical exercise in an aquatic environment, pain perception and cardiovascular autonomic control in adult women suffering from fibromyalgia. The sample consisted of 15 women diagnosed with fibromyalgia who participated in 24 40-minute exercise sessions in a water environment. Anthropometric measures, heart rate variability (HRV) and pain perception (PCS) were evaluated in four experimental times ( $t$ 1, baseline; $t 2$, session $8 ; t 3$, session $16 ; t 4$, session 24 ). In addition, the perception of pain was evaluated in each session through VAS. The results show that the perception of pain through VAS decreased when comparing all the means evaluated before and after each session $(p<0.05)$. In the PCS application, a lower Total Pain and Rumination was obtained when comparing 11 with t4. HRV values showed that SDNN and RMSSD were higher after the session, when t4 was compared with t1 $(p<0.05)$. The mean heart rate decreased at the end of the sessions, showing a better adaptation to exercise. The relationship between pain and cardiac measurements was given by a positive correlation in the pain domains recorded before the sessions and the RMSSD and SDNN values. In conclusion, the practice of physical exercise in an aquatic environment would indicate a lower perception of pain and a better cardiac autonomic response in women with fibromyalgia.

\section{Efectos del ejercicio aeróbico en agua sobre el dolor percibido y la variabilidad cardiaca en mujeres con fibromialgia}




\section{Introduction}

Fibromyalgia (FM) is a disabling disease, recognised by the World Health Organisation with code M79.7 of the International Classification of Diseases (ICD -10 CM)'. Few studies have been conducted in Latin America to investigate its prevalence. However, in 2005, the Clinical Hospital of the University of Chile estimated that $5.4 \%$ of the population suffered from this disease while, at a global level, it is estimated that it affects $5 \%$ of the western population and predominantly women ${ }^{2-5}$. Studies have reported that, in Chile, there is an accelerated increase in its diagnosis over the last few decades, which is consistent with other studies that report a similar rise worldwide ${ }^{2,6}$.

This disease is characterised by giving rise to chronic pain, fatigue, poor physical functioning, sleep alterations and depression, among other symptoms, leading to a predisposition to develop other diseases such as hypertension, overweight, diabetes ${ }^{1,6}$. These disorders affect the perception of pain and its nervous regulation, to become a cyclical health problem that will increase over time $e^{3,7-13}$.

One of the key factors in understanding this disease is its direct relationship with the dysregulation of the autonomic nervous system ${ }^{14}$. One of the principal theories on the etiology of the pain associated with this disease specifically indicates that the causal agent is the central dysregulation of the degree of activity of the sympathetic and parasympathetic nervous systems ${ }^{3,15-18}$, in other words, a dysautonomia or autonomic dysfunction. This dysregulation is characterised by the hyperactivity of the sympathetic nervous system and the hypoactivity of the parasympathetic nervous system ${ }^{5,17}$. The increased sympathetic activity, characteristic of FM, generates a cyclic condition of stress that has a direct impact on $\mathrm{FM}_{\text {sufferers }}{ }^{19}$, a process that would explain the reduced pain tolerance threshold shown by these individuals. Additionally, these cerebral changes affect other organs such as the heart. Therefore, the measurement of the heart frequency variability (HFV) could serve as an indicator of the sympathetic activity level and, therefore, as a possible indicator of this disease ${ }^{20}$, allowing for a more objective evaluation supported by a physiological parameter.

Based on the symptomatology of this disease, aerobic exercise has been studied as a variable that could reduce the perception of pain, reduce fatigue, improve the physical condition, thereby improving the quality of life of individuals ${ }^{21}$. Although many types of exercise stand as viable alternatives to improve the quality of life, for FM there is still no clear relationship between the effects of exercise and autonomic regulation.

Given that the studies are inconclusive on the subject, it is difficult to estimate with certainty, which is the best methodology to promote autonomic changes based on the physical activity performed. In 2004, Gavi, et al., reported that muscle strengthening exercises could reduce the symptoms and improve the quality of life of individuals, yet with no changes to autonomic modulation in fibromyalgia ${ }^{22}$. In contrast, in 2015 Sañudo et al., reported that there were indeed autonomic changes following six months of exercise, directly influencing changes in the levels of anxiety and depression of the subjects ${ }^{23}$. In order to identify these autonomic changes, a validated methodology is the measurement of heart rate variability, which reflects the changes occurring in the heart. These changes are represented by time-domain and frequency-domain measurements, making it possible to estimate the influence of the nervous system on the heart. The consequences of pain include the limitation of physical activity, contributing to the fact that many individuals with FM are overweight ${ }^{24}$, associated with reduced heart rate variability and increased sympathetic activity in the heart ${ }^{25}$. All these works evaluate the many factors that could have an impact on each fibromyalgia sufferer, particularly with regard to the autonomic component, affecting the heart. Therefore, the study of pain variables and autonomic control could provide fresh evidence that would serve to better understand the influence of exercise in the treatment of this disease.

The objective of this study was to describe and relate the changes caused by physical exercise in an aquatic environment with regard to the perception of pain and autonomic cardiovascular control through heart rate variability in adult women suffering from fibromyalgia. Although there are currently a number of alternatives for the non-medical treatment.of fibromyalgia, there is little evidence of quantifiable scientific parameters that serve as a reference for the treatment of the disease. Therefore, any new study will prove useful in the pursuit of a better quality of life for these patients.

\section{Materials and method}

\section{Participants}

25 volunteers selected by non-random accidental sampling took part in this descriptive-correlational study. The inclusion criteria were: female in gender; aged from 30 to 60 years; diagnosed with fibromyalgia by a physiatrist; and receiving no drug treatment that would affect the heart variables or pain-sensitive pathways during the intervention. The study excluded women who were pregnant, with a heart disease, or those whose health was incompatible with the aquatic environment. The study also excluded those participants who did not meet the minimum requirement of $80 \%$ attendance at the water exercise sessions. After applying these criteria, the study sample was reduced to 15 participants, who met all the requirements.

The study was conducted in accordance with the Declaration of Helsinki of 1975, revised in 2008, on the ethical principles for medical research involving human subjects. It also complies with the ethical standards of the committee responsible for medical research involving human subjects of the University of Magallanes. All the women were given general information in personal interviews, in which they were able to resolve all concerns. They subsequently signed the informed consent, prior to taking part in this study.

\section{Instruments}

\section{Body composition}

Bioimpedance served to evaluate the body composition measurements, using the BC-558 Ironman Segmental Body Composition Monitor 
(Tanita Ironman, Arlington Heights, IL 60005 USA) to obtain the following data: weight (Kg.), total muscle mass (Kg.), bone mass (Kg.), total body fat (\%) and basal metabolic rate (Kcal.).

\section{Pain parameters}

In order to analyse the Pain Parameters for each participant, two instruments were used to assess pain perception: Visual Analogue Scale (VAS) and Pain Catastrophizing Scale (PCS) ${ }^{26}$.

The Visual Analogue Scale for pain consists of a $10 \mathrm{~cm}$ long line of cartoon faces showing different pain intensities. The values range from 0, equivalent to "no pain" and 10 "unbearable pain" (Figure 1).

The Pain Catastrophizing Scale measures how catastrophizing thoughts impact on the experience and perception of pain. This scale includes three areas of multidimensional catastrophizing: Rumination; a feeling of constant concern, "I can't stop thinking about how much it hurts" ; Magnification, an exaggeration of the unpleasantness of the pain, "I worry that something serious may happen"; and Helplessness, a loss of hope in achieving something, "There is nothing I can do to reduce the intensity of the pain". Furthermore, this scale gives a Total Pain score that can range from 0 to 52 points. The survey comprises 13 items with 5 -point scales where 0 is never and 4 is all the time. The highest scores indicate higher catastrophizing levels.

\section{Cardiovascular parameters}

To analyse these parameters, Heart Rate Variability (HRV) was measured with the Polar Team2 monitor (Polar ${ }^{\oplus}$, Finland).

The time-domain parameters considered for the analysis were the Root mean square of successive RR interval differences (RMSSD expressed in ms.) that reflect the parasympathetic influence ${ }^{27}$ and the standard deviation of NN intervals (SDNN), which are considered to reflect the total variability, that is the sympathetic and parasympathetic contribution of the autonomic nervous system ${ }^{28,29}$ on the heart. Finally, all the data obtained were digitised using the free Kubios HRV ${ }^{\circledR}$ software ${ }^{30}$.

\section{Perceived effort}

To guide constant work in relation to the exertion of each participant in the course of the study, the 10-point Borg Scale ${ }^{31}$ was used.
This scale has been designed and is recommended for measuring the intensity of physical exertion involving cardiovascular work during patient rehabilitation. A maximum score of 4 was considered, in order to establish a low-intensity aerobic exercise for participants ${ }^{31,32}$.

\section{Procedure}

Each participant, after voluntarily signing the informed consent, was included in the study. For the assessments, participants were requested not to consume tea, coffee or herbal stimulants and not to have taken medicines or drugs in the 12 hours prior to the assessment. Over a 12-week period, each woman took part in two 40-minute weekly sessions of individual and group exercises in an aquatic environment at a constant temperature of $36^{\circ} \mathrm{C}$. The sessions were structured as follows: joint mobility and warm-up; work on upper limbs with material that increased water resistance; lower limb exercises with no added weight, giving priority to moving in the water and raising the heart rate yet always maintaining an aerobic estimation of the activity; cooling down exercises in the water. Each exercise was adapted to each patient based on her daily condition, guided by the Borg perceived exertion scale, considering a score of 4 for each low intensity aerobic activity (the total score of the scale considered for this study was 0 to 10).

The assessment of the body parameters and PCS was conducted at 4 different times: $\mathrm{t} 1$ or baseline, performed prior to the start of the physical exercise sessions in an aquatic environment; $\mathrm{t} 2$, made prior to the 8 th training session in an aquatic environment; 3 , made prior to the 16th training session in an aquatic environment; 4 made prior to the 24th training session in an aquatic environment. In order to assess each of these parameter, the study followed the internal protocols for each assessment instrument. In order to assess perceived pain, the VAS instrument was administered to participants. This instrument was applied at two different times: the first, 5 minutes before the start of the session and then the second was applied 5 minutes after the end of the exercise, during the 24 sessions.

The HRV assessment was performed twice, at each of the assessment times ( $\mathrm{t} 1, \mathrm{t} 2, \mathrm{t} 3$ and $\mathrm{t} 4$ ). The first was conducted after the administration of the questionnaires and prior to the water aerobic

Figure 1. VAS scale based on Vicente-Herrero et al, used to describe the pain perceived by the study participants ${ }^{41}$.

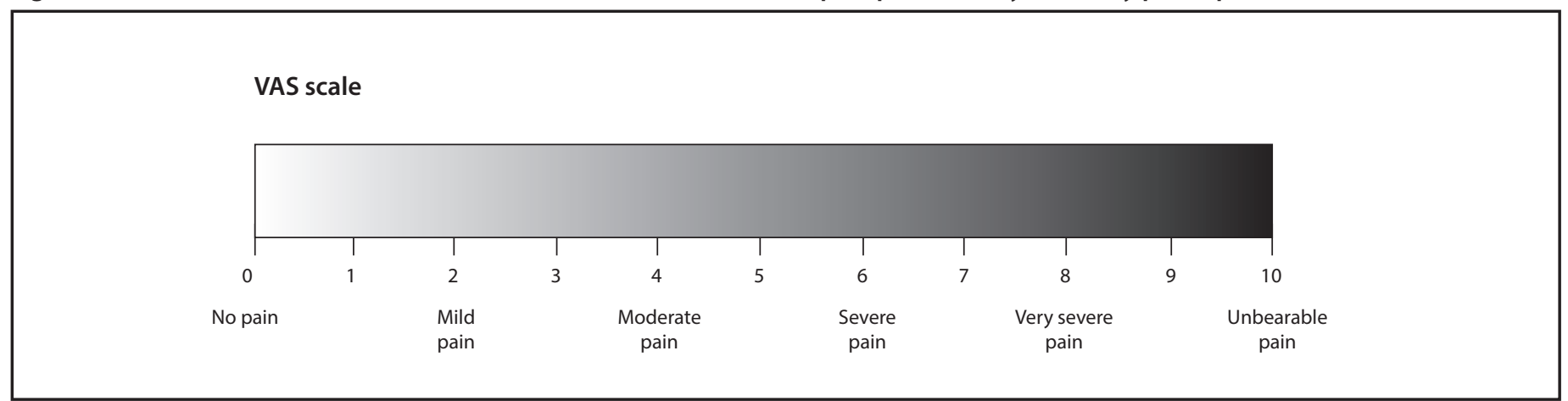


session, while the second was conducted at the end of the physical activity session. In the case of t1 (baseline) the assessment was also repeated twice, allowing 40 minutes between each measurement. For the assessment of this parameter, a chest band holding the Polar device was used. The participant was requested to put on this band with the device and then to sit comfortably, with both feet resting on the floor. She was told that she must remain in that position for around 5 minutes in order to reach an at-rest condition. Once the at-rest condition had been reached, the HRV data were then taken for a time of not less than 10 minutes, during which the participants had to stay calm, without talking and without doing anything that could alter their heart rate. In parallel, a visual assessment was made of the participants' breathing rate for greater precision. This was found to be above 12 cycles per minute. The tachograms generated by the Kubios program were visually inspected in order to exclude defects from artefacts and ectopic beats, not exceeding $3 \%$ of the data recorded.

Annex 1 outlines the protocol for the collection of the data used in this study.

All the data obtained were digitised in a Microsoft Office Excel 2016 spreadsheet. In order to maintain the privacy of the participants, the data were numbered, in other words an alphanumeric value was assigned to the identity of each subject. This ensured that only the investigator responsible would be able to correlate the results obtained with the identity of the participant.

\section{Statistical analysis}

For the statistical analysis, the database was exported to the Statistical Package for the Social Sciences ${ }^{\circledast}$ (IBM SPSS) software, version 24. In order to observe the difference between the four assessment times, a paired sample t test was performed for PCS and the Wilcoxon Test forVAS and HRV parameters. The Spearman correlation coefficient was used to determine the relationships between the PCS and HRV variables while descriptive tests were also conducted on the data compiled. All the analyses were made considering a statistically significant value of $p<0.05$.

\section{Results}

In this study the average age of the participants was 47 years ( \pm 8 years). Their anthropometric measurements are shown in Table 1.

The results of the body composition, observed in Table 2, indicate that 12 of the 15 women were either overweight or obese (BMI > 25).

With regard to the perceived pain assessment using VAS, the statistically significant differences are given by greater values at the start than at the end, with positive ranges $(Z=-11.265 ; p=0.001)$, as observed in Figure 2.

With regard to the rating of pain using the PCS instrument, an analysis was made of the 4 domains assessed. The statistical results show significant differences, as can be seen in Table 3.

With regard to the PCS scores at $t 4$, the scores for Total Pain show a significant difference with $p=0.048$, with $\mathrm{gl}=14$ with regard to 4 , while similar statistical characteristics are given for the Rumination score
Table 1 Anthropometric measurements and body composition of the women included in the sample assessed.

\begin{tabular}{lcccc}
\hline & $\begin{array}{c}\mathbf{t 1} \\
(\mathbf{n}=\mathbf{1 5})\end{array}$ & $\begin{array}{c}\mathbf{t 2} \\
(\mathbf{n}=\mathbf{1 5})\end{array}$ & $\begin{array}{c}\mathbf{t 3} \\
(\mathbf{n}=\mathbf{1 5})\end{array}$ & $\begin{array}{c}\mathbf{t 4} \\
(\mathbf{n}=\mathbf{1 5})\end{array}$ \\
\hline Weight (Kg) & $76.5 \pm 14.1$ & $76.3 \pm 14.4$ & $76.5 \pm 13.7$ & $75.5 \pm 16.7$ \\
BMI & $29.1 \pm 4.01$ & $29.8 \pm 4.32$ & $29.9 \pm 4.42$ & $29.5 \pm 4.63$ \\
$\begin{array}{l}\text { Total muscle } \\
\text { mass (Kg) }\end{array}$ & $44 \pm 4.66$ & $44 \pm 4.64$ & $44.4 \pm 4.49$ & $43.2 \pm 4.55$ \\
$\begin{array}{l}\text { Total body } \\
\text { fat (\%) }\end{array}$ & $38.5 \pm 7.22$ & $38.3 \pm 7.24$ & $38 \pm 7.95$ & $38.3 \pm 8.18$ \\
$\begin{array}{l}\text { Bone } \\
\text { mass (Kg) }\end{array}$ & $2.35 \pm 0.24$ & $2.35 \pm 0.22$ & $2.36 \pm 0.21$ & $2.31 \pm 0.23$ \\
$\begin{array}{l}\text { Basal metabolic } \\
\text { rate (Kcal) }\end{array}$ & $1418 \pm 154$ & $1414 \pm 151$ & $1425 \pm 143$ & $1391 \pm 160$ \\
\hline
\end{tabular}

This table shows the \pm mean standard deviation from the anthropometric measurements and body composition assessed through the Tanita BC-558 Ironman.

Table 2. Sample classification based on BMI.

\begin{tabular}{lcc}
\hline Assessment & BMI Range & Prevalence \\
\hline Healthy & $18.5-24.9$ & 3 \\
Overweight & $25.0-29.9$ & 5 \\
Obese & $30.0-39.9$ & 7 \\
\hline
\end{tabular}

This table created by the authors, shows the distribution of the study participants based on their BMI, following the parameters of the WHO33. Moderate obesity (class I) and severe obesity (class II) are grouped together as a single parameter.

Figure 2. Values for the mean score for the daily VAS record at the start at end of all the exercise sessions in an aquatic environment. The significant differences are described through the following code: ${ }^{*}$, for $p<0.05$.

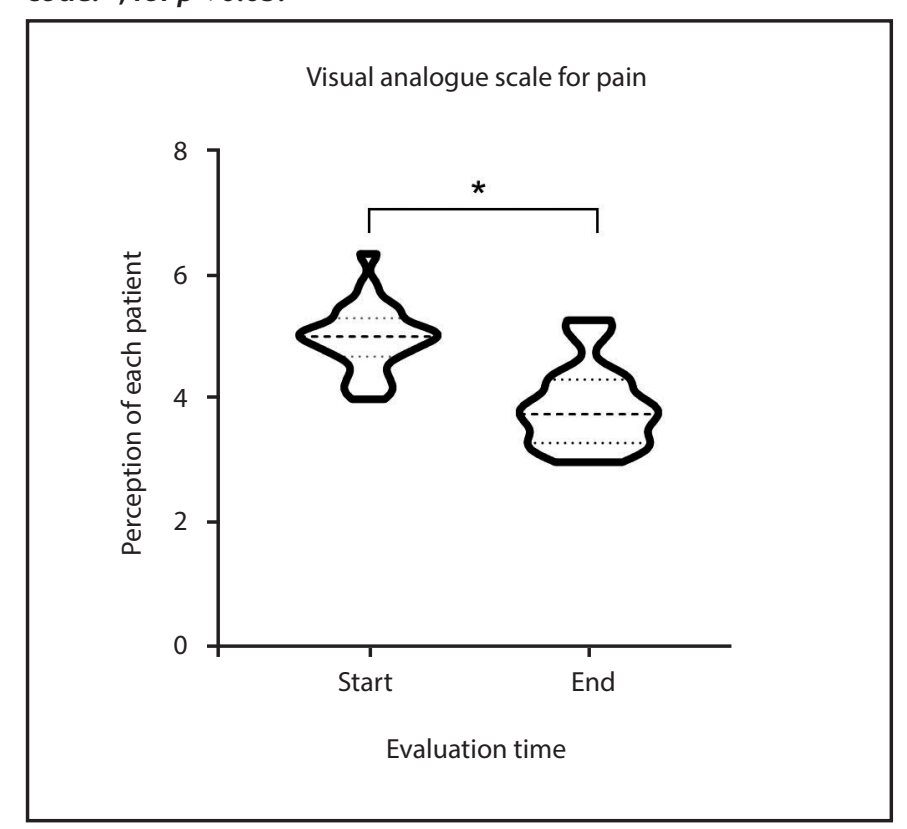


showing $p=0.049$ with the same degree of freedom, as the same study times are compared.

The results of the cardiovascular measurements for the different assessment times are given in table 4. It can be seen that significant differences mainly arise when comparing $t 1$ and $t 3$ with the fourth assessment time (t4). Furthermore, it is possible to observe a progressive reduction in the mean heart rate (HR) of the participants, as the assessments progress, both at the start and end of the intervention. Although this reduction is not significant, it can be explained by an improvement in the physiological adaptation to exercise.

By relating the PCS and VFC variables, it was possible to observe that at $\mathrm{t} 2$ there was a moderate positive correlation between the RMSSD at the start and Magnification $\left(r_{(s)}=0.591, R^{2}=0.34 p=0.020\right)$, and RMSSD with Helplessness $\left(r_{(s)}=0.514, R^{2}=0.26 p=0.050\right)$. Analysing $t 3$, moderate positive correlations were observed between the start measurements for Rumination with SDNN $\left(r_{(s)}=0.533, p=0.041\right)$ and Rumination with $\operatorname{RMSSD}\left(r_{(s)}=0.522, p=0.046\right)$. While for t 4 a moderate positive correlation

Table 3. Scores for the Pain Catastrophizing Scale (PCS).

\begin{tabular}{lcccc}
\hline & $\begin{array}{c}\mathbf{t} 1 \\
(\mathbf{n}=\mathbf{1 5})\end{array}$ & $\begin{array}{c}\mathbf{t 2} \\
(\mathbf{n}=\mathbf{1 5})\end{array}$ & $\begin{array}{c}\mathbf{t 3} \\
(\mathbf{n}=\mathbf{1 5})\end{array}$ & $\begin{array}{c}\mathbf{t 4} \\
(\mathbf{n}=\mathbf{1 5})\end{array}$ \\
\hline Total pain & $25.7 \pm 13.91$ & $18.7 \pm 13.4$ & $19.1 \pm 11.8$ & $15.7 \pm 13.1$ \\
Rumination & $9.13 \pm 5.29$ & $6.20 \pm 4.52$ & $7.13 \pm 4.76$ & $5.47 \pm 4.76$ \\
Magnification & $5.67 \pm 3.64$ & $4.13 \pm 3.62$ & $3.60 \pm 2.77$ & $3.60 \pm 3.18$ \\
Helplessness & $10.9 \pm 6.10$ & $8.40 \pm 5.73$ & $8.40 \pm 5.15$ & $6.67 \pm 5.59$ \\
\hline
\end{tabular}

This table shows the \pm mean standard deviation for each PCS catastrophizing area considered in this study: Rumination; Magnification; Helplessness; Total Pain. The significance is given by values of $p<0,05$ and it is structured according to the following nomenclature: *in relation to 1 .

Table 4. Measurements of the heart rate variability for the different experimental times.

\begin{tabular}{lcccc}
\hline & $\begin{array}{c}\mathbf{t 1} \\
(\mathbf{n}=\mathbf{1 5})\end{array}$ & $\begin{array}{c}\mathbf{t 2} \\
(\mathbf{n}=\mathbf{1 5})\end{array}$ & $\begin{array}{c}\mathbf{t 3} \\
(\mathbf{n}=\mathbf{1 5})\end{array}$ & $\begin{array}{c}\mathbf{t 4} \\
(\mathbf{n}=\mathbf{1 5})\end{array}$ \\
\hline SDNN (ms) & & & & \\
$\begin{array}{l}\text { Input } \\
\text { Output }\end{array}$ & $16.9 \pm 8.69$ & $15.1 \pm 8.28$ & $16.5 \pm 7.18$ & $22.8 \pm 11.7$ \\
RMSSD (ms) & $14.0 \pm 7.18$ & $16.2 \pm 7.89$ & $13.6 \pm 4.55$ & $22.9 \pm 11.7^{\text {ae }}$ \\
$\begin{array}{llll}\text { Input } \\
\text { Output }\end{array}$ & $13.5 \pm 6.62$ & $11.9 \pm 7.25$ & $13.3 \pm 6.92$ & $19.9 \pm 14.5 \mathrm{a}$ \\
$\begin{array}{l}\text { Mean HR (BPM) } \\
\text { Input }\end{array}$ & $12.3 \pm 4.68$ & $10.8 \pm 5.30$ & $9.65 \pm 3.32$ & $18.9 \pm 11.9^{\text {ae }}$ \\
Output & $89.2 \pm 12.5$ & $81.6 \pm 13.9$ & $84.1 \pm 11.2$ & $82.7 \pm 8.64$ \\
\hline
\end{tabular}

This table shows the \pm mean standard deviation for the HRV values considered in this study. SDNN corresponds to the standard deviation of NN intervals shown in milliseconds (ms), RMSSD corresponds to the root mean square of successive RR interval differences expressed in milliseconds (ms), mean HR, corresponds to the mean heart rate of patients, expressed in beats per minute (BPM). The significance is given by values of $p<0,05$ and it is structured according to the following nomenclature: $a$ in relation to $t$; $\mathrm{e}$ in relation to $\mathrm{t} 3$. was observed for the start values of SDNN with Total Pain $\left(r_{(s)}=0.599\right.$, $p=0.018)$ and SDNN with Helplessness $\left(r_{(s)}=0.558, p=0.031\right)$, while RMSSD did so with Magnification $\left(r_{(s)}=0.516, p=0.049\right)$.

When comparing the set of HRV start and end values, no significant differences were obtained between the SDNN values $(Z=-1.406$; $p=0.16$ ), however the RMSSD values did show a significant difference $(Z=-2.506 ; p=0.012)$, showing that the output ranges were greater than the input ranges. The mean heart rate also showed a significant difference between both periods $(Z=-4.461 ; p=0.012)$, indicating that the output ranges were lower than the input ranges.

\section{Discussion}

Fibromyalgia (FM) predisposes the patient to develop different diseases that mainly affect the perception of pain and its nervous regulation, causing a cyclic health problem that constantly affects the quality of life of individuals $\mathrm{s}^{2,3,13}$. Evidence for non-medical treatments of FM point to different therapies that primarily seek to reduce the perception of pain in patients, covering activities such as cognitive-behavioural therapy, acupuncture, mindfulness, massage, hydrotherapy, among others ${ }^{12,33,34}$. Scientific evidence shows that low-intensity physical exercise and, in particular, exercise performed in an aquatic environment, gives the best results in the management of symptomatology 9,13,35. However, chronic pain is one of the key factors limiting the performance of physical exercise in patients, showing a trend to be overweight and obese with BMI values of more than 25 , a characteristic that was also observed in the participants of this study ${ }^{8,10,11}$.

The VAS results observed, show a reduction in the perception of pain when comparing the before and after data of the exercise session. These results are similar to those found in other studies in an aquatic environment where it was observed that, through bio-dance, it was possible to reduce the feeling of pain following the exercise sessions ${ }^{35}$, as well as through physical rehabilitation therapy in water ${ }^{8}$.

When using the PCS to assess the pain, it was interesting to observe a trend towards a reduction in the perception of pain as the exercise sessions progressed, in each domain covered by the test. t4 shows a significant reduction in the feeling of constant concern about pain, as well as in the overall perception of pain, in relation to the baseline time (t1). Although not statistically significant, the domains of Magnification and Helplessness also show a decreasing trend as the exercise sessions progress. These results would indicate that therapy based on physical activity in an aquatic environment would be appropriate for these patients and could have a positive influence on the perception of pain and contribute to the patients' quality of life. However, one limitation of this study was to discern whether the wellbeing achieved through exercise could be affected by the social wellbeing inherent in this type of activity. We therefore consider that future studies should include an assessment of the impact of social environment on physical activity, given that it could also be an influencing factor in the participants' perception of pain. 
With regard to the autonomic regulation (SDNN), the values were seen to be lower than those found in a population of similar characteristics, but without fibromyalgia ${ }^{36}$. However, exercise tends to improve the values as the sessions in the aquatic environment progress, particularly with regard to the heart rate response after completing the session. The progressive increase in the autonomic response was also observed in the parasympathetic response of the patients. The RMSSD values are also lower than for a population without the associated disease ${ }^{36}$, although there was a significant increase in relation to the baseline values as the sessions progressed, both before and after the exercise session. Similar effects on autonomic modulation were not observed in patients with fibromyalgia and subjected to strength training ${ }^{37}$, presumably due to the intensity of the exercise used, while treatments through hydrotherapies have been shown to be the most effective in the nonlinear improvement of HRV in these patients ${ }^{38}$. We hypothesized that the changes perceived could be due to a better adaptation to low-intensity physical exercise that is adjusted to the physiological possibilities of the patient, allowing the patients to progress in line with their own possibilities ${ }^{39}$. Our evidence shows that, when comparing the different measurements for the mean HR at the start, no great changes can be seen, contrary to what was observed with the mean HR at the end. This demonstrated that, with the same effort, which may have been extremely tiring at the beginning, at the end of the intervention it was not so tiring. Therefore, these values imply that exercise would not only permit a reduction in the possibility of suffering FM-related diseases but would also improve the autonomic and cardiovascular regulation of the exercisers.

When relating the values for heart rate and pain, relationships were found between the experimental exercise times but not at the baseline time. The parasympathetic response represented by RMSSD was positively related to PCS pain domains at $\mathrm{t} 2$, $\mathrm{t} 3$ and $\mathrm{t} 4$, always at the start of the session. Similar values were obtained by positively relating the SDNN values for autonomic regulation at the start of $\mathrm{t} 3$ and t4 with the PCS pain domains. Based on the fact that PCS measures the perception of pain during the entire day and that the HRV figures only represent the time of measurement, it could be interpreted that a greater pain domain, predominant in the daily perception of a patient with FM, permits a greater autonomic response to exercise. We consider that this relationship is given for two reasons. Firstly, exercise permits a greater autonomic response to feelings of pain, that is, the individual has a greater response to what he/she perceives as pain and, therefore, a greater tolerance. Secondly, the practice of group activities has additional benefits to those obtained when exercising alone, due to the fact that the socialisation process helps in recovery, by increasing motivation and, consequently, adherence to the physical activity, as shown by other studies ${ }^{34,40}$.

Each of these findings describes the changes that could affect FM sufferers and their response to perceived pain and autonomic heart rate regulation. The results obtained allow us to be confident that heart rate variability could be an objective parameter for monitoring the pro- gress of palliative therapies for patients with fibromyalgia and it could be included as a representative assessment of the autonomic heart rate modulation for this disease. Although we are aware that further studies need to be made, the finding of fresh evidence on the nervous and physiological mechanisms associated with this disease makes it possible to have more alternatives for its diagnosis and, consequently, new strategies for the treatment of the symptomatology of FM, which is extremely important in terms of relieving the constant pain experienced by those diagnosed with FM.

The strengths of the study include: a) the importance of characterising patients with fibromyalgia; b) the assessment of therapies that are currently being conducted in an aquatic environment, as part of the treatment of this disease; c) the type of measuring instruments applied, considering validated questionnaires and objective measurements that could be used in other therapy contexts with patients with fibromyalgia. The main limitations were: a) continuity and strict attendance of each of the sessions; b) the number of participants, which could affect the results. Nevertheless, this study reports new information on little-studied variables that could affect the treatment of patients with fibromyalgia.

\section{Conclusions}

This study would indicate that the practice of aerobic exercise through a program of 24 sessions in an aquatic environment would be associated with a reduction in the perceived pain and a greater autonomic regulation, in women diagnosed with fibromyalgia.

\section{Recognition and Acknowledgements}

We would like to thank the Club de Leones Cruz del Sur de Punta Arenas Rehabilitation Corporation and its team of professionals, for allowing us the use of their treatment centre facilities, as well as each of the patients taking part in this study. We would also like to thank Francisco González and José Fernández for their technical collaboration during this study.

\section{Support for this study}

This project was supported by funds from the National Fund for the Promotion of Sport in Chile, code 1700120150 (National Institute of Sport in Chile, IND).

\section{Conflict of interests}

The authors have no conflict of interest at all.

\section{Bibliography}

1. Wolfe F, Smythe HA, Yunus MB, Bennett RM, Bombardier C, Goldenberg DL, et al. The american college of rheumatology 1990 criteria for the classification of fibromyalgia. Arthritis Rheum. 1990;1;33:160-72.

2. Lefno AL, Contreras GR. Multimorbilidad crónica en mujeres con diagnóstico de fibromialgia en Chile. Arch Med. 2019;19. 
3. Ríos IDP. Actualización en fibromialgia: implicaciones neurofisiológicas y biomecánicas útiles para el abordaje fisioterapéutico. Rev Colomb Rehabil. 2014;13:14-25.

4. Clauw DJ. Fibromyalgia: A clinical review. Vol. 311. JAMA. 2014. p. 1547-55.

5. Casals C, Vázquez Sánchez M, Casals Sánchez J. Prescripción de actividad física en pacientes con fibromialgia. Med Fam. 2011;37:360-6.

6. Miranda JP, Quezada P, Caballero P, Jiménez L, Morales A, Bilbeny N, et al. Revisión sistemática: epidemiología de dolor crónico no oncológico en Chile. Rev El Dolor. 2013;59:10-7.

7. Lizama Lefno A, Rojas Contreras G. Multimorbilidad crónica en mujeres con diagnóstico de fibromialgia en Chile. Arch Med. 2019;19.

8. Gallego AA, Rodríguez AC, Minguet JLC. Análisis de un programa de intervención físico-rehabilitadora estandarizada (Ifre) en medio acuático en mujeres con fibromial gia. Arch Med. 2016;12:9.

9. Marín-Mejía F, Colina-Gallo E, Duque-Vera IL. Danza terapéutica y ejercicio físico. Efecto sobre la fibromialgia. Hacia la Promoción la Salud. 2019;24:17-27.

10. Galiano Orea D, Sañudo Corrales B. Aplicación del ejercicio físico como terapia en medicina del trabajo para pacientes con fibromialgia. Med Segur Trab (Madr). 2013;59:310-21.

11. Corrales BS, Orea DG. Relación entre capacidad cardiorrespiratoria y fibromialgia en mujeres. Reumatol Clínica. 2008;4:8-12.

12. Molina FMC, García AB. Tratamiento integral de la fibromialgia: el ejercicio físico en mujeres adultas. Rev Española Educ Física y Deport. 2020:71-100.

13. del Castillo LAE. Actividad física y fibromialgia, estudio de caso. Mov Científico. 2018;12:55-62.

14. Martinez-Lavin M. Biology and therapy of fibromyalgia. Stress, the stress response system, and fibromyalgia. Arthritis Res Ther. $2007 ; 9: 216$.

15. Martínez Lavin M. Análisis cibernéticos de la variabilidad de la frecuencia cardíaca en pacientes con fibromialgia. Arch Card Mex. 2004;74:485-8.

16. Corrales BS, Orea DG, Páez LC, Saxton J, de Hoyo Lora M. Respuesta autónoma e influencia sobre la calidad de vida de mujeres con fibromialgia tras una intervención de ejercicio físico a largo plazo. Rehabilitación. 2010;44:244-9.

17. Lledó A, Fernández-Díez E, Pastor M, López-Roig S, Ibáñez Ballesteros J, Sorinas Nerín J. Funcionamiento del sistema nervioso autónomo y estado de salud en la fibromialgia. Rev Psicopatología y Psicol Clínica. 2016;21:119-28.

18. Villalpando MIB, Sotres JFC, Cabrera DM, León DG. Disminución del influjo parasimpático en fibromialgia: Su relación con la Psiquiatría en un centro especializado de referencia nacional. Salud Ment. 2015;38:123-8.

19. Van Houdenhove B, Egle UT. Fibromyalgia: A stress disorder? Psychother Psychosom. 2004;73:267-75.

20. Villalpando MIB, Sotres JFC, Cabrera DM, León DG. Disminución del influjo parasimpático en fibromialgia: Su relación con la Psiquiatría en un centro especializado de referencia nacional. Salud Ment. 2015;38:123-8.

21. Busch AJ, Webber SC, Richards RS, Bidonde J, Schachter CL, Schafer LA, et al. Resistance exercise training for fibromyalgia. In: Busch AJ, editor. Cochrane Database of Systematic Reviews. Chichester, UK: John Wiley \& Sons, Ltd; 2013.
22. Gavi MBRO, Vassalo DV, Amaral FT, Macedo DCF, Gava PL, Dantas EM, et al. Strengthening exercises improve symptoms and quality of life but do not change autonomic modulation in fibromyalgia: a randomized clinical trial. PLoS One. 2014;9.

23. Sañudo B, Carrasco L, de Hoyo M, Figueroa A, Saxton JM. Vagal modulation and symptomatology following a 6-month aerobic exercise program for women with fibromyalgia. Clin Exp Rheumatol. ;33:S41-5.

24. Ursini F, Naty S, Grembiale RD. Fibromyalgia and obesity: the hidden link. Rheumatol Int. 2011;31:1403-8.

25. Hassett AL, Radvanski DC, Vaschillo EG, Vaschillo B, Sigal LH, Karavidas MK, et al. A pilot study of the efficacy of heart rate variability (HRV) biofeedback in patients with fibromyalgia. Appl Psychophysiol Biofeedback. 2007;32:1-10.

26. García Campayo J, Rodero B, Alda M, Sobradiel N, Montero J, Moreno S. Validación de la versión española de la escala de la catastrofización ante el dolor (Pain Catastrophizing Scale) en la fibromialgia. Med Clin. 2008;131:487-93.

27. Buchheit M, Chivot A, Parouty J, Mercier D, Al Haddad H, Laursen PB, et al. Monitoring endurance running performance using cardiac parasympathetic function. Eur J Appl Physiol. 2010;108:1153-67.

28. Berntson GG, Bigger JT, Eckberg DL, Grossman P, Kaufmann PG, Malik M, et al. Heart rate variability: Origins, methods, and interpretive caveats. Psychophysiology. 1997;34: 623-48.

29. Buchheit M, Gindre C. Cardiac parasympathetic regulation: respective associations with cardiorespiratory fitness and training load. Am J Physio/ Circ Physiol. 2006;291:H451-8.

30. Tarvainen MP, Niskanen J-P, Lipponen JA, Ranta-Aho PO, Karjalainen PA. Kubios HRV-heart rate variability analysis software. Comput Methods Programs Biomed. 2014; 113:210-20.

31. Borg GAV. Psychophysical bases of perceived exertion. Med Sci Sport Exerc. 1982;

32. Burkhalter N. Evaluation of Borg's perceived exertion scale in cardiac rehabilitation. Rev Lat Am Enfermagem. 1996:4:65-73.

33. Moreno GM. Definición y clasificación de la obesidad. Rev Médica Clínica Las Condes. 2012;23:124-8.

34. Rodríguez SF, Otero LA. Abordaje del paciente con fibromialgia en Atención Primaria. RqREnfCom. 2015;3:25-42.

35. del Mar López-Rodríguez M, Castro-Sánchez AM, Fernández-Martínez M, Matarán-Penarrocha GA, Rodríguez-Ferrer ME. Comparación entre biodanza en medio acuático y stretching en la mejora de la calidad de vida y dolor en los pacientes con fibromialgia. Atención Primaria. 2012;44:641-9.

36. Nunan D, Sandercock Grh, Brodie Da. A Quantitative Systematic Review of Normal Values for Short-Term Heart Rate Variability in Healthy Adults. Pacing Clin Electrophysiol. 2010;33:1407-17.

37. Kingsley JD. Autonomic dysfunction in women with fibromyalgia. Arthritis Res Ther. 2012;14:9-10.

38. Zamunér AR, Andrade CP, Forti M, Marchi A, Milan J, Avila MA, et al. Effects of a hydrotherapy programme on symbolic and complexity dynamics of heart rate variability and aerobic capacity in fibromyalgia patients. Clin Exp Rheumatol. 2015;33:S73-81.

39. Taggart HM, Arslanian CL, Bae S, Singh K. Effects of T'ai Chi Exercise on Fibromyalgia Symptoms and Health-Related Quality of Life. Orthop Nurs. 2003;22:353-60.

40. Porro Novo J, Pereira AE, García AR, Suárez Martín R, Méndez BG. Guía para la rehabilitación de la fibromialgia. Rev Cuba Reumatol. 2015;17:147-56. 